\title{
MODELING AND OPTIMIZATION OF AN ELECTRIC POWER DISTRIBUTION NETWORK PLANNING SYSTEM USING MIXED BINARY INTEGER PROGRAMMING
}

\author{
L. Ogunwolu ${ }^{1,}$, O. Ero ${ }^{2}$ and O. Ibidapo-Obe ${ }^{3}$ \\ 1,2,3 Department of Systems EngineERING, FACUlty of EnGineERING, University of LAGos, LAGos State, NiGERIA. \\ E-mail addresses:1 1fogunwolu@unilag.edu.ng, 2eroewaen@gmail.com, ${ }^{3}$ oyeibidapoobe@gmail.com
}

\begin{abstract}
In this paper, the electric distribution network expansion planning problem (EDNEPP) was solved by a mixed binary integer programming (MBIP) formulation of the network, where the steady-state operation of the network was modelled with non-linear mathematical expressions. The non-linear terms are linearized, using piecewise linearization of the nonlinear expressions, so as to ensure the model computational compatibility with existing commercial optimization solvers. The linearized formulation is verified to ensure its solution optimality and degree of error deviation. The proposed network model formulation considers the alternatives of installation of new transformers of various capacities to reinforce already existing ones at substations of the network, choosing and construction of new substations given feasible locations, re-conductoring of existing feeders in the network, construction of new feeders given various conductor types alternatives, cost lost as a result of power interruption, and changes in the overall network topology. The cost of interruption would contain a cost term called 'cost of goodwill', which was brought into the model formulation, to measure the loss in confidence of consumers to distributors of power as a result of interrupted power supply, which is prevalent in developing nations. Two test systems of 23 and 54 nodes was used in showing the efficiency of the proposed network model formulation.
\end{abstract}

Keywords: Distribution network, mixed binary integer programming, linearization, re-conducting, optimization.

\section{INTRODUCTION}

The alternatives to be considered in planning of an electric power distribution network system can be tasking, owing to the fact that, a wide range of possibilities of configurations that exist in the selection of network facilities. The electric distribution network expansion planning problem (EDNEPP) is to determine the optimal location and capacities of substations, and optimal feeders route paths which would provide electric power to a given set of load demand nodes at the barest minimum cost, with acceptable levels of efficiency and reliability, while fulfilling all the required technical constraints.

The EDNEPP has been traditionally solved in two ways [1]: the static approach and the multistage approach. In the static approach, only one planning horizon is considered in the determination of the optimized network facilities to be installed or added to the existing system. The multistage approach involves not only determination of optimal network facilities, but also the ideal time these facilities are to be assimilated into the network system, so as to ensure an overall optimized network cost to cater for the increase at each load demand nodes in the network at the nearest future. In this paper, the static approach was covered, while the multistage approach, was handled by using a pseudodynamic planning approach, where the multistage problem was solved by series of single period problems, consisting of separate planning year horizon. The disadvantage of this approach is that the resulting solution, would not be overall optimal, as current solution for each horizon planning is not influenced by future decision during the optimization process.

Several power distribution planning methods or algorithms, have been developed to address the EDNEPP. These methods differ in the degree of accuracy, complexity and application. These methods fall into two categories [2]: Mathematical Programming Methods (Deterministic Algorithms) and the Heuristic Methods (Heuristic-based Algorithms).

A significant number of studies have been devoted to the optimisation of distribution systems using the deterministic based algorithms, among which includes: [3] which proposed a two-stage solution methodology for distribution network planning considering reliability indices, by formulating the problem of optimal expansion 
of the radial distribution system as a mixed binary integer linear programming (MBILP). The methodology used, improved the network reliability by allocating sectionalized switches and interconnection circuits. [4] proposed a mixed integer linear model formulation for use in the problem of multistage planning of energy distribution systems including distributed generation. A constructive heuristic algorithm (CHA) is proposed in [5] for the EDNEPP. In that work, the binary decision variables of the mixed binary integer non-linear problem (MBINLP) are relaxed making the problem a nonlinear programming (NLP) problem. The NLP problem is solved iteratively to calculate a sensitivity index that is used in the CHA. Finally, a heuristic local improvement phase is used to improve the solution found by the CHA. In their paper [6] titled "A mixed-integer linear programming approach for optimal type, size and allocation of distributed generation in radial distribution systems", the authors formulated the steady-state operation of a radial distribution system, considering different load levels, and the short-circuit capacity of the circuits, using linear expressions. A major contribution of the paper, was in the method proposed in linearizing the power flow constraints of the Non-linear mathematical model, which presents an efficient computational behaviour with conventional MBILP solvers. Other MBILP models are developed in [1, 7 - 9]. Each of these determine the optimal locations and capacities of substations and feeder paths of the network. In [10] and [11] a quadratic model is used to model the EDNEPP. [2] used a dynamic programming approach in simultaneously optimizing both the cost and reliability of the distribution network. Both Non-Iterative and Iterative two-step dynamic programming methods were proposed, for the optimization of the feeder routes and branch conductor sizes. The report in [12] compared two methods of the Long Run Marginal Cost (LRMC) namely the Average Incremental Cost (AIC) and the Marginal Incremental Cost (MIC) methods to determine the LMRC of transmission and distribution expansion/reinforcement of power systems.

Some of the Heuristic based techniques that have been used in solving the EDNEPP includes genetic algorithm, which was used in [13 - 15]. The genetic based approach, usually involves representation of decision variables of the EDNEPP as chromosomes, after which series of crossover and mutation operations through successive generations are carried out in search for the optimal solution. Another heuristic approach also used is the simulated annealing, which was used in [16] and [17]. This heuristic based technique is derived from the annealing process, which usually involves reduction of the overall network capital cost of the system stepwisely, by removing the most capital cost effective branch, among the available set, as long as the feasible solution arrived at, satisfies the technical constraints and connectivity of the network. Other heuristic methods used are the Ant colony algorithm used in [18], the Tabusearch algorithm used in [19] and [20]. In [21] Artificial Neural Network (ANN) was used in addressing power quality problems prevalent in power distribution network.

In this paper a MBINLP formulation to solve the EDNEPP is introduced. The MBINLP model is linearized using a piecewise linearization of the nonlinear curve function terms, so as to ensure the proposed model formulation's computational compatibility with conventional mixed integer programming optimization solvers. The proposed network model formulation considers the alternatives of construction/repowering of substations of the network given various capacities of transformers to be employed, construction/reconductoring of feeder sections given various conductor types and changes in the overall network topology by minimization of the investments cost, operating network cost, overall network losses and the cost lost as a result of power interruption, while considering the loss in goodwill of customers, as a result of interrupted power supply. This paper is structured as follows: in section2, the list of notational symbols used in the model formulation is presented, in section 3 , a MBINLP model for the EDNEPP is introduced; the MBINLP model is also linearized in section 3. The results showing the performance of the proposed formulation is presented in 4. Finally in section 5 conclusion of the results achieved is presented.

\section{LIST OF SYMBOLS}

The symbols used throughout this paper are exhibited in this section for quick reference.

\section{1 Model sets}

$\Omega_{\mathrm{F}}$ is the Set of conductor types, $\Omega_{\mathrm{L}}$ is theSet of branches (Both existing and new), $\Omega_{\mathrm{d}}$ is the Set of load demand nodes,

$\Omega_{\mathrm{S}}$ is the Set of substations nodes (Both existing and new), $\Omega_{\mathrm{T}}$ is the Set of transformer_types

\subsection{Model parameters}

$\mathrm{C}_{\mathrm{ij}, \mathrm{f}}^{\mathrm{n}}$ is the Construction cost of new feeder circuit $i j$, using conductor type $f$ (Naira/KM), and $\mathrm{C}_{\mathrm{ij}, \mathrm{a}, \mathrm{f}}^{\mathrm{r}}$ is the Reconductoring cost of existing circuit $i j$, from Conductor type a, to conductor type $f, l_{i j}=$ length of ciruit ij (in $\mathrm{km}$ ) 
$q_{i j}$ is the Binary connectivity matrix,

$\mathrm{C}_{\mathrm{t}}^{S}$ is the cost of construction/Reinforcement at substation $\mathrm{S}$ of transfomer type $\mathrm{t}$ (Naira)

$\mathrm{R}_{f}$ is the Resistance of conductor type $\mathrm{F}(\mathrm{n} / \mathrm{km}), \mathrm{X}_{f}$ isthe Reactance of conductor type $\mathrm{F}(\mathrm{n} / \mathrm{km})$

$\mathrm{H}$ is the Number hours in a year (8760 hours)

$C_{E}$ is the Cost of Energy (Naira/kwh), $\quad \phi_{l}$ is the Loss load factor of circuits, $t$ is the Total planning time ,r is the Perceived interest rate, $P\left(t_{d}, r\right)$ is the Present worth value function

$C_{s}$ is the Operating cost of substation, at node $\mathrm{s}\left(\mathrm{Naira} /(\mathrm{KW})^{2} / \mathrm{H}\right), \phi_{s}$ is the Loss load factor, of substation at node $\mathrm{s}$, $D_{i j, f}$ is the branch $i j$ average failure duration (in Hours), $\lambda_{i j, f}$ is the conductor type $f$ failure rates,

$\mathrm{C}_{\mathrm{s}}^{l}$ is the Cost of loss of Goodwill of customers (Customer Damage cost) at node $i$,

$Y$ is the Number of desired discretisation interval,

$\Delta I^{\text {max }}{ }_{f}$ is the Maximum value for currentflow piecewise linearized curve function, of conductor type $f$

$\Delta P^{\max }{ }_{f}$ is the Maximum value for power flow piecewise linearized curve function, of conductor type $f$

$\Delta S^{\max }{ }_{i}$ is the Maximum value for power generated at substation piecewise linearized curve function.

$I_{y}^{f}$ is the Gradient for current descretized curve function

$M i j_{y}^{f}$ is the Gradient for powerflow descretized curve function

$S_{y}^{i}$ is the Gradient for power generated at substation descretized curve function

$V^{\text {max }}$ is the maximum allowed voltage magnitude $(K V)$

$V_{\text {min }}$ is the minimum allowed voltage magnitude $(K V)$

$\mathrm{P}_{s}^{\text {ext }}$ is the maximum apparent power of existent substation $s$

$\mathrm{P}_{t, s}^{\text {new }}$ is the power to be constructed/reinforced of transformer type t, at substation $s$

$N^{d}$ is the number of nodes in the network

$N^{s}$ is the number of substation nodes in the network

\subsection{Model Variables}

$y_{i j, f}$ is the Binary Decision Variable for Construction/Reconductoring of feeder's lines.

$\mathrm{w}_{\mathrm{t}}^{S}$ is the Binary decision variable for construction/Reinforcement of substation $\mathrm{s}$

$I_{i j, f}$ is the current flowing in ciruit $i j$, associated with conductor type $\mathrm{f}$

$\mathrm{A}_{\mathrm{s}}$ is the Apparent Power provided by substation $\mathrm{s}$

$\mathrm{P}_{\mathrm{s}}$ is the Real Power provided by substation $\mathrm{s}$

$\mathrm{Q}_{\mathrm{s}}$ is the Reactive Power provided by substation $\mathrm{s}$

$A_{i j, f}^{f l o w}$ is the Apparent Power flow in circuits $i j$ of conductor type $f$

$P_{i j, f}^{f l o w}$ is the Real Power flow in circuits $i j$ of conductor type $f$

$Q_{i j, f}^{f l o w}$ is the Reactive Power flow in circuits $i j$ of conductor type $f$

$\Delta I_{i j, y}^{f}$ is the discretizational variables of nonlinear current function

$\Delta P_{i j, y}^{f}$ is the discretizational variables of nonlinear real power flow function

$\Delta Q_{i j, y}^{f}$ is thediscretizational variables of nonlinear reactive power flow function

$\Delta P_{y}^{i}$ is thediscretizational variables of nonlinear real power supply function

$\Delta Q_{y}^{i}$ is thediscretizational variables of nonlinear reactive supply function

\section{METHODOLOGY}

\subsection{TheMBINLP model for EDNEPP}

In this section, the EDNEPP is modelled as a MBINLP. The works of [5], [2], [10] and [22] inspired the equations used in formulation of the proposed model. They are presented below.

Minimize Total Network Cost (TNC):

$$
\begin{gathered}
\sum_{i j \in \Omega_{\mathrm{L}}} \sum_{f \in \Omega_{\mathrm{F}}} \mathrm{C}_{\mathrm{ij}, \mathrm{f}}^{\mathrm{n}} l_{i j} y_{i j, f}\left(1-q_{i j}\right)+\sum_{i j \in \Omega_{\mathrm{L}}} \sum_{f \in \Omega_{\mathrm{F}}} \mathrm{C}_{\mathrm{ij}, \mathrm{a}, \mathrm{f}}^{\mathrm{r}} l_{i j} y_{i j, f} q_{i j}+\sum_{s \in \Omega_{\mathrm{s}}} \sum_{t \in \Omega_{\mathrm{t}}} \mathrm{C}_{\mathrm{t}}^{S} \mathrm{w}_{\mathrm{t}}^{s}+\sum_{i j \in \Omega_{\mathrm{L}}} \sum_{f \in \Omega_{\mathrm{F}}} P\left(t_{d}, r\right) \mathrm{H} C_{E} \phi_{l}\left(I_{i j, f}\right)^{2} \mathrm{R}_{f} l_{i j} \\
+P\left(t_{d}, r\right) \times \sum_{s \in \Omega_{\mathrm{s}}} \mathrm{A}_{\mathrm{s}}^{2} C_{s}+\sum_{i j \in \Omega_{\mathrm{L}}} \sum_{f \in \Omega_{\mathrm{F}}} P\left(t_{d}, r\right) \mathrm{H}\left\{C_{E}+\mathrm{C}_{\mathrm{zs}}^{l} D_{i j, f}\right\} \lambda_{i j, f} A_{i j, f}^{f l o w}
\end{gathered}
$$

Subject to: 


$$
\begin{gathered}
\sum_{j i \in \Omega_{\mathrm{L}}} \sum_{f \in \Omega_{\mathrm{F}}}\left(P_{j i, f}^{f l o w}-I_{j i, f}^{2} \mathrm{R}_{f} l_{j i}\right)+P_{s}^{d}=P_{i}^{d}+\sum_{i j \in \Omega_{\mathrm{L}}} \sum_{f \in \Omega_{\mathrm{F}}} P_{i j, f}^{f l o w} ; \text { for each } \mathrm{i}, \mathrm{j} \in \Omega_{\mathrm{d}} \\
\sum_{j i \in \Omega_{\mathrm{L}}} \sum_{f \in \Omega_{\mathrm{F}}}\left(Q_{j i, f}^{f l o w}-I_{j i, f}{ }^{2} \mathrm{X}_{f} l_{j i}\right)+Q_{s,}^{d}=Q_{i}^{d}+\sum_{i j \in \Omega_{\mathrm{L}}} \sum_{f \in \Omega_{\mathrm{F}}} Q_{i j, f}^{f l o w} ; \text { for each } \mathrm{i}, \mathrm{j} \in \Omega_{\mathrm{d}}
\end{gathered}
$$

$$
\begin{aligned}
& V_{\text {min }} \leq V_{i} \leq V^{\max } ; \quad \text { for each } \mathrm{i} \in \Omega_{\mathrm{d}} \\
& \sum_{f \in \Omega_{F}} y_{i j, f} \leq 1 ; \quad \text { for each } i j \in \Omega_{\mathrm{L}} \\
& \sum_{i j \in \Omega_{\mathrm{L}}} \sum_{f \in \Omega_{\mathrm{F}}} y_{i j, f}=N^{d}-N^{s} \\
& \left(A_{i j, f}^{\text {flow }}\right)^{2} \leq\left(V^{\max }\right)^{2} \times\left(I_{f}^{\max }\right)^{2} \times y_{i j, f} ; \quad \text { for each } i j \\
& \in \Omega_{\mathrm{L}}, f \in \Omega_{\mathrm{F}} \\
& A_{i j, f}^{\text {flow }^{2}}=P_{i j, f}^{\text {flow }^{2}}+Q_{i j, f}^{\text {flow }}{ }^{2} ; \quad \text { for each } i j \\
& \in \Omega_{\mathrm{L}} \text { and } f \in \Omega_{\mathrm{F}} \\
& \left(I_{i j, f}\right)^{2} \leq\left(I_{f}^{\max }\right)^{2} \times y_{i j, f} ; \quad \text { for each } i j \\
& \in \Omega_{\mathrm{L}} \text { and } f \in \Omega_{\mathrm{F}} \\
& \left(I_{i j, f}\right)^{2}=\frac{\left(A_{i j, f}^{\text {flow }}\right)^{2}}{\left(V_{i}\right)^{2}} \quad \text { for each } \mathrm{i}, \in \Omega_{\mathrm{d}}, i j \\
& \in \Omega_{\mathrm{L}} \text { and } f \in \Omega_{\mathrm{F}} \\
& \mathrm{A}_{\mathrm{s}}^{2}=\mathrm{P}_{\mathrm{s}}^{2}+\mathrm{Q}_{\mathrm{s}}^{2} \text { for each } \mathrm{s} \in \Omega_{\mathrm{s}} \\
& \mathrm{A}_{\mathrm{s}}^{2} \leq\left(\mathrm{P}_{s}^{\mathrm{ext}}+\sum_{t \in \Omega_{\mathrm{t}}} \mathrm{P}_{s}^{\mathrm{new}} \mathrm{w}_{\mathrm{t}}^{s}\right)^{2} ; \text { for each } s \in \Omega_{s} \\
& V_{s}^{\text {nominal }}{ }^{2}\left(\sum_{i j \in \Omega_{\mathrm{L}}} \sum_{f \in \Omega_{\mathrm{F}}}\left(I_{i j, f}\right)^{2}\right) \leq \mathrm{A}_{\mathrm{s}}^{2} ; \quad \text { for each } s \\
& \in \Omega_{s}
\end{aligned}
$$

The objective function (1) comprises of the costs of installing new facilities and expansion of existing facilities. The component costs are due to energy losses, operation of the substations in the network, and losses as a result of power interruption. The first and second parts of the objective function represent the cost of installation of new feeder branches and reconductoring of existing feeder branches respectively. The third part is the fixed cost associated with the network, it involves the cost of constructing new substations (cost of lands, erecting feeder's lines etc.) and the cost of reinforcement of existing substations (the purchase of new transformer capacities to augment existing transformers capacity at a given substation). The fourth, fifth and sixth parts of the objective function involve the costs associated with energy losses, operation of the substations in the network, and losses as a result of power interruption respectively. The function $P\left(t_{d}, r\right)=\left(1-(1+r)^{-t}\right) / r$ is used to calculate the present value cost in future terms. The cost incurred as a result of power interruption includes a cost associated with the loss in goodwill of consumers to suppliers of electric power in the network. The model of the distribution network formulated must satisfy constraints (2) - (13). Constraints (2) and (3) represent the conventional power balance at any given node i, which is common to any network model. Constraints (4) set limits on the voltage magnitude across any node. Constraints (5) ensures the selection of only one conductor type for any given feeder branch. Constraints (6), coupled with constraints (2) and (3) are used to ensure a radial operation of the network system as shown in [23].Constraints (8) and (7) show the relationship between active and reactive power flow in the network and sets a limit on the apparent power flow in the network respectively. Constraints (9) and (10) set a limit on current flow in each feeder branch and shows theohmic relationship between the apparent power flow and current flow. Constraints (11) show the relationship between active and reactive power supply in the network. Constraints (12) are constraints that set limits on the apparent power supply at the substations, as well as serve as a model for the construction/repowering of substations of the network given various types of transformer capacities to choose from. Constraints (13) not a necessary condition for a feasible solution, but a sufficient one, serve to also limit the power flow into a substation of the network, so as not to exceed its capacity.

\subsection{Linearization of the non-linear terms of the proposed MBINLP for the EDNEPP}

In the MBINLP formulation of the power distribution network, there exists non-linear terms (such as the square of the current flow) both in the objective function and in the constraints. These non-linear terms behaves very poorly with commercial mixed integer optimization solvers. In other words for a relatively small problem size, the number of nodes required by the Branch and Bound optimization process coupled with the solution time required by the optimization process could be very large and there exists a possibility of the optimization process never converging. This justifies the use of linearization techniques that would approximate these nonlinear functions.

\subsubsection{Linearization of the Square of the Current Flow}

$$
\begin{aligned}
& \left(I_{i j, f}\right)^{2}=\sum_{y=1}^{Y} I_{y}^{f} \Delta I_{i j, y}^{f} ; \text { for each } i j \in \Omega_{\mathrm{L}} \text { and } f \in \Omega_{\mathrm{F}} \\
& I_{i j, f}=\sum_{y=1}^{Y} \Delta I_{i j, y}^{f} ; \text { for each } i j \in \Omega_{\mathrm{L}} \text { and } f \in \Omega_{\mathrm{F}}
\end{aligned}
$$




$$
\begin{gathered}
\Delta I_{i j, y}^{f} \leq \Delta I_{f}^{\max } ; \quad \text { for each } y=1,2, \ldots, Y, i j \\
\in \Omega_{\mathrm{L}} \text { and } f \in \Omega_{\mathrm{F}}
\end{gathered}
$$

Where $\Delta I_{f}^{\max }=\frac{\left(I_{f}^{\max }\right)}{Y}$ and $I_{y}^{f}=(2 y-1) \Delta I_{f}^{\text {max }}$

Equation (14) shows that the relationship between the square of current flow and the slope of the discretized nonlinear current flow curve function. Equation (15) shows that the current flow in any branch, is the sum of all discretized variables of the nonlinear current curve function. Equation (16) sets limits on each discretized variable.

\subsubsection{Linearization of Square of The Relationship Between} Real and Reactive Power Flow in the Network

$$
\begin{gathered}
\left(A_{i j, f}^{\text {flow }}\right)^{2}=\sum_{y=1}^{Y} \operatorname{Mij}_{y}^{f}\left(\Delta P_{i j, y}^{f}+\Delta Q_{i j, y}^{f}\right) \quad \text { for each } i j \\
P_{i j, f}^{\text {flow }}=\sum_{y=1}^{Y} \Delta P_{\mathrm{L}}^{f} \text { and } f \in \Omega_{\mathrm{F}} \\
\in \Omega_{\mathrm{F}} \\
Q_{i j, f}^{\text {flow }}=\sum_{y=1}^{Y} \Delta Q_{i j, y}^{f} \quad \text { for each } i j \in \Omega_{\mathrm{L}} \text { and } f \\
\in \Omega_{\mathrm{F}} \\
\Delta P_{i j, y}^{f} \leq \Delta P_{f}^{\text {max }} ; \quad \text { for each } i j \in \Omega_{\mathrm{L}} \text { and } f \\
\in \Omega_{\mathrm{L}} \text { and } f \in \Omega_{\mathrm{F}} \\
\Delta Q_{i j, y}^{f} \leq \Delta P_{f}^{\text {max }} ; \quad \text { for each } y=1,2, \ldots, Y, i j \\
\in \Omega_{\mathrm{L}} \text { and } f \in \Omega_{\mathrm{F}}
\end{gathered}
$$

Where $\Delta P^{\max }=\left(V^{\max } \times I_{f}^{\max }\right) / Y$ and $\quad$ Mij $_{y}^{f}=$ $(2 y-1) \Delta P_{f}^{\max }$

Equation (17) shows the relationship between the apparent power flow, slope and discretised variables of the nonlinear curve function. Equations (18) and (19) show that the active and reactive power flow is the sum of the discretised variables of the non-linear curve function. Equations (20) and (21) set limits on the discretised variables.

\subsubsection{Linearization of Square of the Relationship Between Real And Reactive Power Supply At Substations In The Network}

$$
\mathrm{A}_{\mathrm{s}}^{2}=\sum_{y=1}^{Y} S_{y}^{i}\left(\Delta P_{y}^{i}+\Delta Q_{y}^{i}\right) ; \quad \text { for each } s
$$

$\in \Omega_{S}$

$$
P_{i, z}^{d}=\sum_{y=1}^{Y} \Delta P_{y}^{i} ; \quad \text { for each } \mathrm{s}
$$

$\in \Omega_{\mathrm{s}}$

$$
Q_{i, z}^{d}=\sum_{y=1}^{Y} \Delta Q_{y}^{i} \quad \text { for each } s
$$

$\in \Omega_{s}$

$$
\Delta P_{y}^{i} \leq \Delta S_{i}^{\max } ; \quad \text { for each s }
$$

$\in \Omega_{\mathrm{s}}$

$$
\Delta Q_{y}^{i} \leq \Delta S^{\max }{ }_{i} \text { for each } s
$$

$\in \Omega_{S}$

Where

$\Delta S_{i}^{\max }=\left(\mathrm{P}_{Z, S}^{\text {ext }}+\right.$ maximum power to be added $)$

$$
/ Y \text { and } S_{y}^{i}=(2 y-1) * \Delta S_{i}^{\max }
$$

Equations (22) shows the relationship between the apparent power supply, slope and discretised variables of the nonlinear curve function. Equations (23) and (24) show that the active and reactive power supply is the sum of the discretised variables of the non-linear curve function. Equations (25) and (26) set limits on the discretised variables.

Also the right hand side of constraints (12) was linearized by algebraic expansion of the quadratic function as shown in equation (27)

$$
\begin{aligned}
& \left(\mathrm{P}_{s}^{\mathrm{ext}}+\sum_{t \in \Omega_{\mathrm{t}}} \mathrm{P}_{s}^{\text {new }} \mathrm{w}_{\mathrm{t}}^{s}\right)^{2} \\
& =\left(\mathrm{P}_{s}^{\mathrm{ext}}\right)^{2}+2 \times \mathrm{P}_{s}^{\mathrm{ext}} \times \sum_{t \in \Omega_{\mathrm{t}}} \mathrm{P}_{s}^{\text {new }} \mathrm{w}_{\mathrm{t}}^{s} \\
& +\left(\mathrm{P}_{s}^{\text {new }}\right)^{2} \mathrm{w}_{\mathrm{t}}^{s} ;
\end{aligned}
$$

The square of the voltage magnitude in constraint (10) was linearized by using a constant voltage source for that equation as proposed in [1]. This was verified experimentally after performing several simulations for different ranges of voltage magnitudes.

\subsection{The MBILP Model for EDNEPP}

In summary, the Linearized Model of the Power distribution network can be written by replacing all the non-linear terms, by their linear counterparts. The linearized model can thus be written as:

Min (1)

Subject to Constraints (2) - (10), (13),(14) - (27) where all non-linear terms are replaced by their linear counter-parts.

\section{TESTS AND RESULTS}

The MBNLIP model of the electric power distribution network was implemented in AMPL[24] and solved in CPLEX[25] using a workstation with Intel ® Core ${ }^{\mathrm{TM}}$ i7 4500U CPU @ 1.8GHz. The proposed Linearized Model was first verified using a simple test node problem, consisting of 5 nodes. The model was then tested for both static and multistage planning of the network using two test distribution systems of 23 and 54 nodes. The data for the test problems are a modification of the ones 
used in [16] and [26] respectively and are depicted in Appendix Tables 1, 2, and 3.

\subsection{Verification of Linearized Model Formulation}

The linearized network model, would be verified by using a simple test power distribution planning problem, consisting of 5 nodes (1 substation node and 4 load node) as shown in figure 1 .

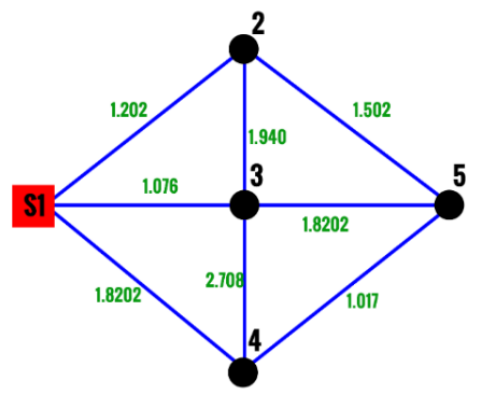

Figure 1: Test Problem feasible paths for verification of Linearized Model

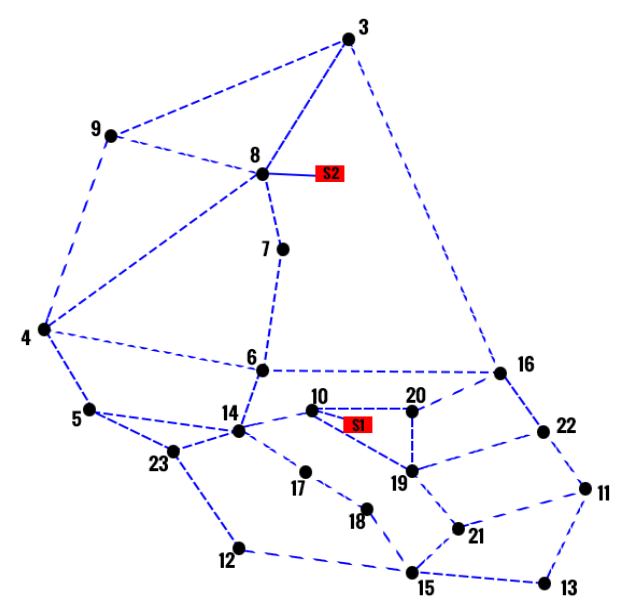

Figure 2: Network of feasible paths for 23-node static expansion problem

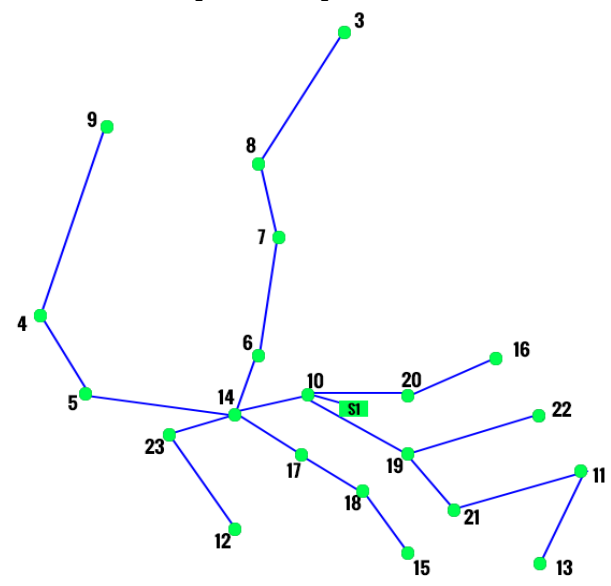

Figure 3: Solution for the distribution network proposed plan for the 23 node network for 20 -year plan horizon

The test problem would be solved both linearly and nonlinearly, so as to estimate the deviations of both model solutions. The non-linear formulation would be solved using the optimization solver KNITRO [27]. The problem is to determine the optimal feeder conductor paths routing from substation $\mathrm{S} 1$, while satisfying the technical constraints of the network. The results for the optimization test problem for a 5-year planning horizon, using both the non-linear and the linearized model formulations is given in table I. The Solution of the nonlinear problem consisting of 89 variables was found after evaluating 85 nodes of the branch and bound algorithm with a computational time of 2.82 seconds (2.547 CPU time) and a total network cost of $\$ 283300$. The Solution of the linear model formulation with a discretization value of 400 (chosen experimentally, as this value preserved the accuracy of the gotten solution), was found after 98 Mixed Integer Problem (MIP) simplex iterations, with a computational time of 0.34 seconds (CPU time) and a total network cost of \$283984. Both model formulation constructed the same circuit configuration which consisted of 4 circuits, all of conductor type 1 .

\subsection{Test case 1: Static Expansion Planning of a 23 Node Distribution Network}

The problem of selecting optimal $11 \mathrm{kv}$ feeder routing and optimal location for a 10MVA, 23-node distribution system to feed the demands at an oil producing area with 21 load nodes was considered. The circuits can be built using two type of conductors which cost $\$ 10000$ and $\$ 20000$ respectively. The permissible voltage drop across any branch is $3 \%$; the cost of energy is $\$ 0.1 / \mathrm{KWh}$; the perceived interest rate used was 0.1 ; loss factor of circuits and substations is 0.35 ; transformer types used for substation construction are 7.5 and 15 MVA, with a substation fixed costs of $\$ 40000$ and $\$ 70000$ for both types of transformers. The customer damage cost and duration of possible outage in the network is $0.0001 /$ hour and 88 hours. The failure rates for conductor types used are 0.2 and 0.1 for type 1 and 2 respectively. A planning horizon of 20 years was considered. Technical characteristics of the conductor type used are shown in Table 2 and the proposed feasible routes are displayed in Figure 2.

The result of the optimization of the static expansion planning of the 10 MVA $11 \mathrm{KV} 23$ node power distribution network is given in the Figure 3 and Table 3. The Solution of the MBILP problem with a discretization value of 135 (chosen experimentally, as this value preserved the accuracy of the gotten solution) was found after evaluating 104 nodes of the branch and bound algorithm (1595 MIP Simplex Iterations) with a computational time of 2.66 seconds (CPU time) and a total network cost of \$343599.The proposed model constructed a single new substation at one of the given set of feasible locations, installing a 7.5MVA transformer at the substation. It also constructed 20 new circuits of 
conductor type 1 and one circuit branch $(1,10)$ of conductor type 2 , disconnecting 14 feasible circuit paths. The working capacity of the installed transformer was maximum 7.0523MVA for the 20-year planning horizon.

Table I: Comparison of solutions for Non-Linear and Linearized Model formulations

\begin{tabular}{lccc}
\hline NETWORK COST & NON-LINEAR MODEL & LINEARIZED MODEL & PERCENTAGE ERROR \\
& SOLUTION(\$) & SOLUTION(\$) & $0.241 \%$ \\
\hline Total Network Cost & 283300 & 283984 & $0 \%$ \\
Cost of Installation & 51150 & 51150 & $40.26 \%$ \\
Cost of Power Losses & 57.7813 & 81.0454 & $0.13 \%$ \\
Cost lost due to & 18706.9 & 18731 & $0.129 \%$ \\
interruption & & 214022 & \\
Operating Cost of & 213385 & & \\
Substation & & & \\
\hline
\end{tabular}

Table 2: Technical Characteristics of Conductor types ([16], [26])

\begin{tabular}{|c|c|c|c|c|}
\hline Conductor Types & Resistance $(\Omega / K m)$ & Reactance $(\Omega / K m)$ & Maximum Current & Cost (\$) \\
\hline 1 & 0.3655 & 0.2520 & $150 \mathrm{~A}$ & 10000 \\
\hline 2 & 0.2921 & 0.2466 & $200 \mathrm{~A}$ & 20000 \\
\hline
\end{tabular}

Table3: Network Costs Results from Optimization Process of 23 node static expansion planning power distribution system for 20 year horizon planning period

\begin{tabular}{ccccc}
\hline Network System & $\begin{array}{c}\text { Cost Of Circuits } \\
\text { Installation (\$) }\end{array}$ & $\begin{array}{c}\text { Cost Of } \\
\text { Energy } \\
\text { Losses }(\$)\end{array}$ & $\begin{array}{c}\text { Operating Cost }(\$) \\
\text { ( Cost Lost As A Result Of } \\
\text { Power Interruption }\end{array}$ & $\begin{array}{c}\text { Total Cost } \\
(\$)\end{array}$ \\
\hline $\begin{array}{c}23 \text { Node, } 10 \mathrm{mva}, \\
11 \mathrm{kv}\end{array}$ & 154800 & 425.375 & 129822 & 18551.5 \\
\hline
\end{tabular}

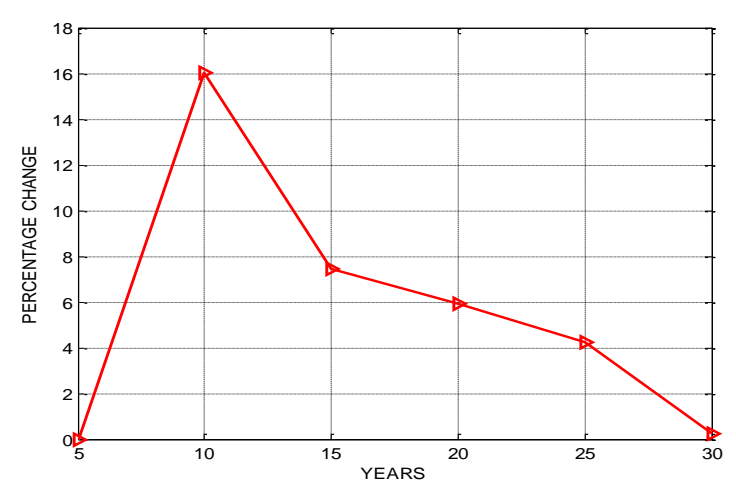

Figure 4: Plot of Percentage Change in Network Cost for Different Time Horizon of the 23 node system

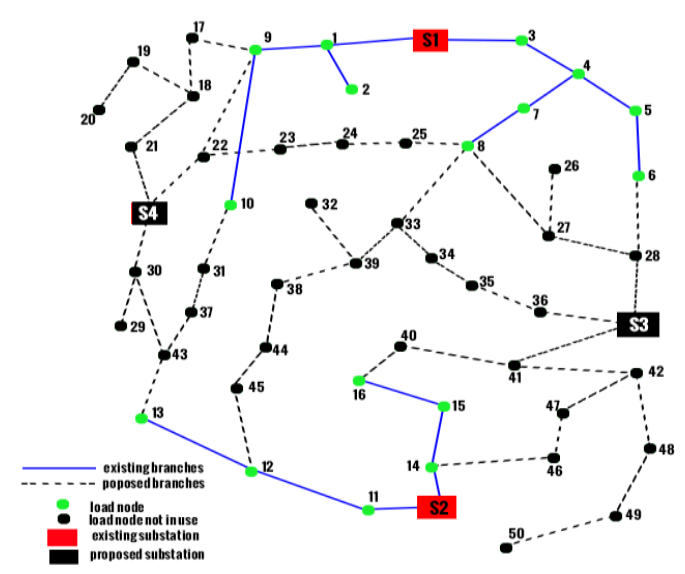

Figure 5: Network of feasible paths for the 54 node dynamic expansion problem

\subsection{Test case 2: Multistage expansion planning of a 54} node distribution network

In this Test Case, the expansion planning of a 54 node power distribution system with Nominal voltage of $11 \mathrm{KV}$ feeding 50 load nodes, and supplying 70 MVA was considered. The Network has 2 existing substations that can be reinforced and there is also a possibility of the construction of 2 more substations. A planning horizon of 20 years, at 5 years' intervals was considered and each at each time horizon, an increase of $15 \%$ at the load demand nodes was assumed. The circuits can be built using same conductor types as test case 1 . The permissible voltage drop across any branch is 3\%; the cost of energy is $\$ 0.1 / \mathrm{KWh}$; the perceived interest rate used was 0.1 ; loss factor of circuits and substations is 0.35; transformer types used for substation construction are 15 and 30 MVA, with a substation fixed costs of $\$ 70000$ and $\$ 122500$, for both types of transformers. The existing capacities of substations are 50MVA.The customer damage cost and duration of possible outage in the network is 0.0001 /hour and 88 hours. The failure rates for conductor types used are 0.2 and 0.1 for types 1 
and 2 respectively. The feasible routes are displayed in figure 5.

The result of the solution for the optimization of the 54 node dynamic expansion plan for the 54 node distribution network is shown in Figure 6, Tables 5 and 6. At the first planning horizon (5years), the proposed model constructed the two substation at the given location, both using transformer type 2 (30 MVA) 25 new circuits was constructed, all of conductor type1. One existing circuit was disconnected, and 3 of the existing circuits, was reconductored to conductor type 2. Both existing substations were working at a capacity of 20.92MVA and 21.62MVA (for Substation1 and substation 2 respectively), while the newly constructed substations were working at a capacity of 19.55MVA and 18.31MVA (for substations 3 and 4 respectively)

At the second planning horizon (10 years) the model reconductored 5 existing circuits to that of conductor type2 (making a total of 6 circuits using that conductor type) both existing substations were working at a capacity of 24.37MVA and 25.46MVA (for substation1 and substation2respectively), while the newly constructed substations were working at a capacity of 22.88MVA and 21.57MVA (for substations 3 and 4 respectively)

At the third planning horizon (15 years) the model retained same circuit configuration with same conductor types employed except for branch $(11-12)$ which was reconductored to conductor type 2. Both existing substations were working at a capacity of 28.66MVA and 31.23MVA (for substation 1 and substation 2 respectively), while the newly constructed substations were working at a capacity of 27.51MVA and 26.48MVA (for substations 3 and 4 respectively)

At the fourth planning horizon (20 years) the model reinforced substation 3 with a 15 MVA transformer type. The model reconductored 1 existing circuit to that of conductor type 2, making it a total of 10 circuits, using that conductor type. Both existing substations were working at a capacity of 32.51MVA and 34.56MVA (for substations 1 and 2 respectively), while the constructed substations were working at a capacity of 30.69MVA and 29.14MVA (for substations 3 and 4 respectively)

\section{CONCLUSIONS}

A mixed binary linear programming (MBLIP) model for the problem of planning of the electric power distribution network was presented in this paper. This would serve as a very important tool for designers and investors, in the planning of the electric power network system, as real-time decision making policies can be built around this model, so as to obtain an optimized network cost plan throughout the lifespan of the network system. The use of MBLIP formulation has the advantage of nice computational compatibility with conventional mixed integer programming optimization solvers, as well as robust solutions, similar to that of the non-linear formulation with very low error of approximations, which was verified. This model is not only restricted to power distribution network, it can also be employed in transmission and generation network, as this all fall under the category of network models, which this model formulation is suitable for.

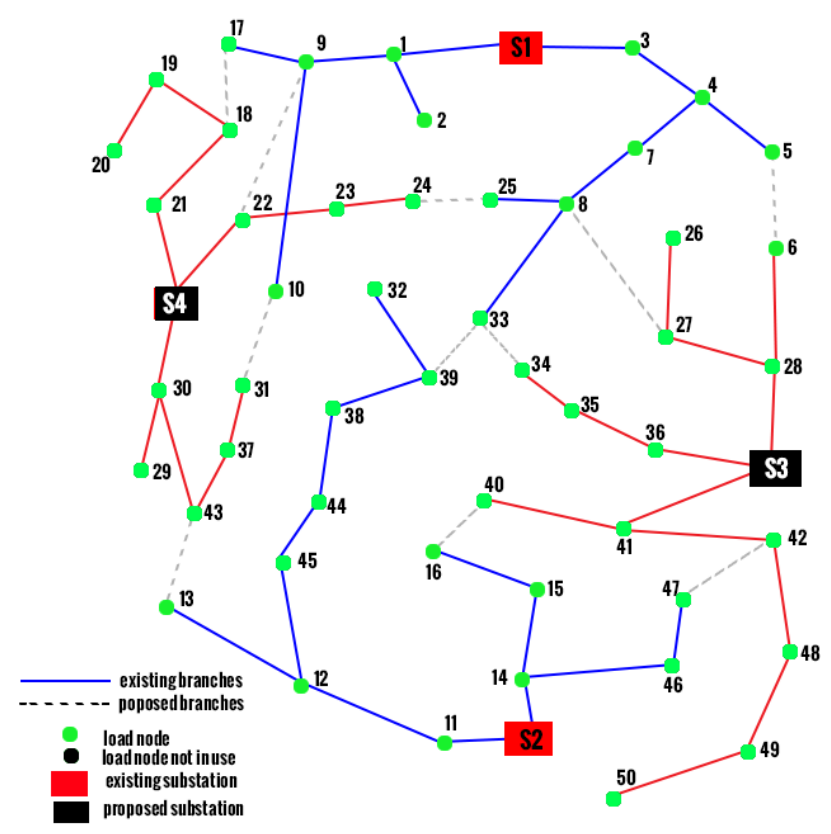

Figure 6: Solution for the distribution network proposed plan for the 54 node network planning horizon

Table 5: Network Costs Results from Optimization Process of the 54-node distribution system for various planning horizon

\begin{tabular}{|c|c|c|c|c|c|}
\hline $\begin{array}{l}\text { PLANNING } \\
\text { HORIZON } \\
\text { (Years) }\end{array}$ & $\begin{array}{c}\text { COST OF } \\
\text { ENERGY LOSS } \\
(\$)\end{array}$ & $\begin{array}{c}\text { COST OF POWER } \\
\text { INTERRUPTION } \\
(\$)\end{array}$ & $\begin{array}{c}\text { COST OF CIRCUITS } \\
\text { INSTALLATION } \\
(\$)\end{array}$ & $\begin{array}{l}\text { OPERATING } \\
\text { COST } \\
(\$)\end{array}$ & $\begin{array}{l}\text { TOTAL } \\
\text { COST } \\
(\$)\end{array}$ \\
\hline 5 & 4699.12 & 131976 & 254487 & 1885250 & 2521410 \\
\hline 10 & 11545.7 & 228342 & 274511 & 4201340 & 4960740 \\
\hline 15 & 27126.8 & 349507 & 264431 & 7588800 & 8474860 \\
\hline 20 & 25909 & 407929 & 15364 & 10550500 & 11594500 \\
\hline
\end{tabular}


Table 6: Percentage Change in Network Cost over the 20 year Planning Horizon for 54 node test distribution system

\begin{tabular}{|c|c|c|c|c|c|}
\hline $\begin{array}{l}\text { PLANNING } \\
\text { HORIZON } \\
\text { (YEAR) } \\
(\$)\end{array}$ & $\begin{array}{c}\text { TOTAL } \\
\text { NETWORK } \\
\text { COST } \\
(\$)\end{array}$ & $\begin{array}{l}\text { OPERATING } \\
\text { COST } \\
(\$)\end{array}$ & $\begin{array}{c}\text { COST OF } \\
\text { ENERGY LOSS } \\
(\$)\end{array}$ & $\begin{array}{l}\text { COST OF POWER } \\
\text { INTERRUPTION } \\
(\$)\end{array}$ & $\begin{array}{c}\text { PERCENTAGE } \\
\text { INCREASE OF } \\
\text { NETWORK COSTS } \\
\text { FROM PREVIOUS YEAR }\end{array}$ \\
\hline 5 & 2521410 & 1885250 & 4699.12 & 131976 & $-\%,-\%-\%,-\%$ \\
\hline 10 & 4960740 & 4201340 & 11545.7 & 228342 & $\begin{array}{c}96.75 \%, 122.85 \% \\
145.7 \%, 73.02 \%\end{array}$ \\
\hline 15 & 8474860 & 7588800 & 27126.8 & 349507 & $\begin{array}{c}70.84 \%, 80.63 \% \\
134.95 \%, 53.06 \%\end{array}$ \\
\hline 20 & 11594500 & 10550500 & 25909 & 407929 & $\begin{array}{c}36.81 \%, 39.03 \% \\
4.49 \%, 16.72 \%\end{array}$ \\
\hline
\end{tabular}

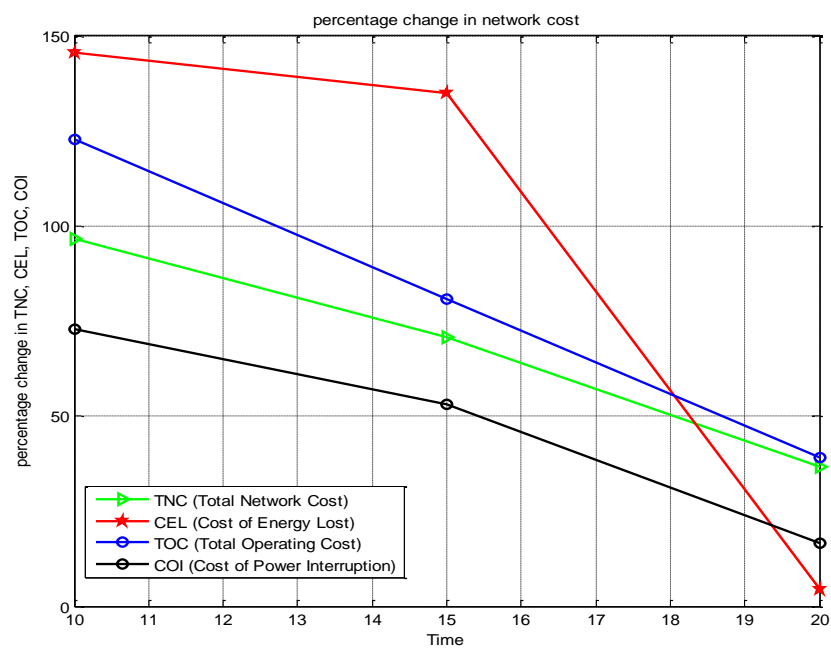

Figure7:Plot of percentage change in network costs over entire planning horizon

\section{REFERENCES}

[1] Pozos, A. T., de Oliveira, M. L., Baquero, J. F. F., \& Flores, M. J. R. "A mixed-binary linear formulation for the distribution system expansion planning problem", Transmission \& Distribution Conference and Exposition-Latin America (PES T\&D-LA), EEE PES, IEEE., , pp. 1 - 6. 2014.

[2 ] Ganguly, S., Sahoo, N. C., \& Das, D. "Multi-objective planning of electrical distribution systems using dynamic programming", International Journal of Electrical Power \& Energy Systems, 46, pp. 65 78. 2013,

[3] de Souza, J., Rider, M. J., \& Mantovani, J. R. S. "Planning of Distribution Systems Using Mixed-Integer Linear Programming Models Considering Network Reliability." Journal of Control, Automation and Electrical Systems, 26(2), pp. 170 - 179. 2015,

[4] Haffner, S., Pereira, L. F. A., Pereira, L. A., \& Barreto, L. S. "Multistage model for distribution expansion planning with distributed generation-Part I: Problem formulation", Power Delivery, IEEE Transactions on, 23(2), pp. 915 - 923. 2008,

[5] Lavorato, M., Rider, M. J., Garcia, A. V., \& Romero, R. "A constructive heuristic algorithm for distribution system planning", Power Systems, IEEE Transactions on, 25(3), pp. 1734 - 1742. 2010,

[6] Rueda-Medina, A. C., Franco, J. F., Rider, M. J., PadilhaFeltrin, A., \& Romero, R. "A mixed-integer linear programming approach for optimal type, size and allocation of distributed generation in radial distribution systems." Electric power systems research, 97, pp. 133-143. 2013,

[7] Omu, A., Choudhary, R., \& Boies, A. "Distributed energy resource system optimisation using mixed integer linear programming", Energy Policy, 61, pp. 249 - 266. 2013,

[8] Gönen, T. and I. J. Ramirez-Rosado. "Optimal multistage planning of power distribution systems", Power Delivery, IEEE Transactions on, 2(2), pp. 512 - 519. 1987,

[9] Wall, D. L., Thompson, G. L., \& Northcote-Green, J. E. D. "An optimization model for planning radial distribution networks", IEEE Transactions on Power Apparatus and Systems, 3(PAS-98), pp. 1061 - 1068. 1979,

[10] Ponnavaikko, N., Rao, K. P., \& Venkata, S. S. "Distribution system planning through a quadratic mixed integer programming approach", Power Delivery, IEEE Transactions on, 2(4), pp. 1157 1163. 1987,

[11] Bhowmik, S. G., PK Bhattacherjee, S. "Distribution system planning through combined heuristic and quadratic programing approach", Electric Machines \&Power Systems, 28(1),: pp. 87 - 103. 2000,

[12] Ekwue, A. O. “Assessment of Long-Run Marginal Costing of Transmission and Distribution Expansion", Nigerian Journal of Technology, Vol. 33 (3), pp. 245 - 251. 2014,.

[13] Falaghi, H., Singh, C., Haghifam, M. R., \& Ramezani, M. "DG integrated multistage distribution system expansion planning", International Journal of Electrical Power \& Energy Systems, 33(8), pp1489 - 1497. 2011,

Vol. 36, No. 2, April 2017 
[14]Rivas-Davalos, F. and M. Irving. "An efficient genetic algorithm for optimal large-scale power distribution network planning", Power Tech Conference Proceedings, June 23, 2003 IEEE Bologna, Vol. 3, pp. 5-pp. 2003,

[15] TÜRKAY, B. and T. ARTAÇ. "Optimal distribution network design using genetic algorithms", Electric Power Components and Systems, 33(5), pp. 513 524. 2005,

[16] Nahman, J. M. and D. M. Peric. "Optimal planning of radial distribution networks by simulated annealing technique", Power Systems, IEEE Transactions on, 23(2), pp. 790 - 795. 2008,

[17]Parada, V., Ferland, J. A., Arias, M., \& Daniels, K. "Optimization of electrical distribution feeders using simulated annealing", Power Delivery, IEEE Transactions on, 19(3), pp. 1135 - 1141. 2004,

[18] Gomez, J. F., Khodr, H. M., De Oliveira, P. M., Ocque, L., Yusta, J. M., Villasana, R., \& Urdaneta, A. J. "Ant colony system algorithm for the planning of primary distribution circuits", Power Systems, IEEE Transactions on, 19(2), pp. 996 - 1004. 2004,

[19] Ramírez-Rosado, I. J. and J. A. Domínguez-Navarro. "New multiobjective tabu search algorithm for fuzzy optimal planning of power distribution systems", Power Systems, IEEE Transactions on, 21(1), pp.224 - 233. 2006,

[20] Wen, F. and C. Chang. "Transmission network optimal planning using the tabu search method." Electric power systems research, 42(2), pp153 163. 1997,
[21] Uhumnwangho, R., Omorogiuwa, E. and Offor, G. "Voltage Compensation using Artificial Neural Network: A case Study of Rumuola Distribution Network", Nigerian Journal of Technology, Vol. 36 (1), pp. 178 - 185. 2017,

[22] Franco, J. F., Rider, M. J., Lavorato, M., \& Romero, R. "Optimal conductor size selection and reconductoring in radial distribution systems using a mixed-integer LP approach", Power Systems, IEEE Transactions on, 28(1), , pp. 10 - 20 . 2013.

[23] Lavorato, M., Franco, J. F., Rider, M. J., \& Romero, R. "Imposing radiality constraints in distribution system optimization problems", IEEE Transactions on Power Systems, 27(1), pp. 172 - 180. 2012,

[24] Fourer, R., Gay, D. M., \& Kernighan, B. W. "A modeling language for mathematical programming", Management Science, 36(5), 0, pp. 519 - 554. 199

[25] ILOG, S. (2008). "CPLEX optimization subroutine library guide and reference." System v11. 0 User's Guide.

[26] Miranda, V., Ranito, J. V., \& Proenca, L. M. "Genetic algorithms in optimal multistage distribution network planning", IEEE Transactions on Power Systems, 9(4), , pp. 1927 - 1933. 1994

[27] Byrd, R. H., Nocedal, J., \& Waltz, R. A. "KNITRO: An integrated package for nonlinear optimization", Large-scale nonlinear optimization, Springer, pp. 35 - 59. 2006,

\section{APPENDIX}

The input data for the models developed are depicted in Appendix Tables 1, 2 and 3 below.

Appendix Table 1: Network parameters for 23-node test network.

\begin{tabular}{|c|c|c|c|c|c|c|}
\hline Node & $1 *$ & $2 *$ & 3 & 4 & 5 & 6 \\
\hline Connectivity & 10 & 8 & 9 & 8,9 & 4,23 & $4,7,16$ \\
\hline Conductor & 0.20 & 0.08 & 1.82 & $2.31,0.94$ & $0.94,0.64$ & $0.81,1.5$, \\
\hline Length (km) & & & & & & 1.171 \\
\hline $\begin{array}{l}\text { Real Power } \\
\text { Demand }(\mathrm{kW})\end{array}$ & 0 & 0 & 0.320 & 0.320 & 0.320 & 0.320 \\
\hline Node & 7 & 8 & 9 & 10 & 11 & 12 \\
\hline Connectivity & 8 & 9 & 3 & $14,19,20$ & 13 & 15 \\
\hline $\begin{array}{l}\text { Conductor } \\
\text { Length }(\mathrm{km})\end{array}$ & 0.69 & 2.06 & 1.82 & $0.43,0.6,0.7$ & 0.51 & 0.98 \\
\hline $\begin{array}{l}\text { Real Power } \\
\text { Demand }(\mathrm{kW})\end{array}$ & 0.320 & 0.320 & 0.320 & 0.320 & 0.320 & 0.320 \\
\hline Node & 13 & 14 & 15 & 16 & 17 & 18 \\
\hline Connectivity & 15 & $6,5,17,23$ & 6 & 22,3 & 18 & 15 \\
\hline Conductor & & 1.02, 0.82, & 0.98 & $0.95,4.22$ & 0.44 & 0.57 \\
\hline Length (km) & & $0.45,0.49$ & & & & \\
\hline $\begin{array}{l}\text { Real Power } \\
\text { Demand }(\mathrm{kW})\end{array}$ & 0.320 & 0.320 & 0.320 & 0.320 & 0.320 & 0.320 \\
\hline Node & 19 & 20 & 21 & 22 & 23 & \\
\hline Connectivity & $20,21,22$ & 16 & 11 & 11 & 12 & \\
\hline Conductor & $0.73,0.56$ & 0.5 & 0.64 & 0.69 & 0.68 & \\
\hline
\end{tabular}


Length (m) $\quad 0.58$

Demand $(\mathrm{kW})$

0.320

0.320

0.320

0.320

0.320

*Substations

Appendix Table 2: Technical Characteristics of Conductor types

\begin{tabular}{|c|c|c|c|c|}
\hline Conductor Types & Resistance $(\Omega / K m)$ & Reactance $(\Omega / K m)$ & Maximum Current & $\operatorname{Cost}(\$)$ \\
\hline 1 & 0.3655 & 0.2520 & $150 \mathrm{~A}$ & 10000 \\
\hline 2 & 0.2921 & 0.2466 & $200 \mathrm{~A}$ & 20000 \\
\hline
\end{tabular}

Appendix Table 3: Network parameters for the 54-node test network

\begin{tabular}{|c|c|c|c|c|c|c|}
\hline Node & S1 & 1 & 3 & 4 & 5 & 7 \\
\hline Connectivity & 1,3 & 2,9 & 4 & 5,7 & 6 & 8 \\
\hline Conductor Length (km) & $0.1405,1.09$ & $0.56,0.715$ & 0.1208 & $0.308,0.098$ & 0.345 & 0.098 \\
\hline Real Power Demand (kW) & 0 & 3.15 & 1.525 & 1.825 & 1.375 & 1.525 \\
\hline Node & 8 & 9 & 11 & 12 & 13 & 14 \\
\hline Connectivity & 25,33 & 17,10 & 12 & 13,45 & 43 & 15,46 \\
\hline Conductor Length (km) & $0.098,0.290$ & $0.56,0.723$ & 0.56 & $0.985,0.7250$ & 0.785 & $0.875,0.715$ \\
\hline Real Power Demand (kW) & 1.75 & 1.425 & 2.175 & 2.25 & 1.35 & 1.825 \\
\hline Node & 15 & 16 & 18 & 19 & & \\
\hline Connectivity & 16 & 40 & 19 & 20 & & \\
\hline Conductor Length (km) & 0.7405 & 0.405 & 0.25 & 1.56 & & \\
\hline Real Power Demand (kW) & 0.75 & 1.050 & 1.525 & 0.9 & & \\
\hline Node & S4 & 22 & 23 & 28 & 27 & 31 \\
\hline Connectivity & $21,22,30$ & 23,9 & 24 & 6,27 & 8,26 & 10 \\
\hline Conductor Length (km) & $0.25,1.875,1.405$ & $0.715,0.085$ & 0.405 & $0.089,0.56$ & $0.923,0.715$ & 0.56 \\
\hline Real Power Demand (kW) & 0 & 1.35 & 1.825 & 1.125 & 0.9 & 1.95 \\
\hline Node & 21 & 24 & S3 & 30 & 37 & 38 \\
\hline Connectivity & 18 & 25 & 28,3641 & 29 & 31 & 39 \\
\hline Conductor Length (km) & 0.56 & 1.09 & $0.56,0.725,0.56$ & 0.56 & 0.935 & 0.935 \\
\hline Real Power Demand (kW) & 0.6 & 1.75 & 0 & 0.583 & 0.875 & 0.458 \\
\hline Node & 39 & 34 & 35 & 36 & 43 & 44 \\
\hline Connectivity & 32 & 33 & 34 & 35 & 37 & 38 \\
\hline Conductor Length (km) & 2.03 & 0.935 & 0.79 & 0.590 & 0.550 & 0.56 \\
\hline Real Power Demand (kW) & 0.4167 & 1.2083 & 0.375 & 1.250 & 0.5417 & 0.583 \\
\hline Node & 33 & 41 & 30 & 45 & 46 & 42 \\
\hline Connectivity & 39 & 42,40 & 43 & 44 & 47 & 48 \\
\hline Conductor Length (km) & 0.605 & $0.875,0.55$ & 0.630 & 0.79 & 0.56 & 0.7250 \\
\hline Real Power Demand (kW) & 0.7083 & 0.375 & 0.583 & 0.333 & 0.75 & 0.5 \\
\hline Node & 48 & 49 & & & & \\
\hline Connectivity & 49 & 50 & & & & \\
\hline Conductor Length (km) & 0.875 & 0.79 & & & & \\
\hline Real Power Demand (kW) & 0.3333 & 0.2083 & & & & \\
\hline
\end{tabular}

